\title{
La apertura a la Vida como don, herida y morada. Diálogos entre una artista visual y una teóloga moralista en torno a la hospitalidad
}

\author{
Isabel Pena \\ Escuela Superior de Bellas Artes Regina Pacis \\ San Isidro, Buenos Aires, Argentina \\ isapenia@yahoo.com.ar \\ Silvina Astigueta * \\ Pontificia Universidad Católica Argentina \\ silvina.astigueta@gmail.com \\ Recibido 20.12.2020/ Aprobado 06.02.2021 \\ DOI: https://doi.org/10.46553/teo.58.134.2021.p91-108
}

\section{RESUMEN:}

En este artículo se ponen en diálogo la ética teológica y la estética, en las voces de una teóloga moralista y de una artista visual quienes, asomadas a las obras de algunos artistas -como ser Alejandro Crotto, Hilma Af Klint, Francis Alys, y la misma Isabel Peña- observan la hospitalidad como apertura a la vida. Hospitalidad que se encarna en la ética teológica como estilo configurador, enraizado en la experiencia fundante del Dios que hospeda, y en el arte como acogida del don vital que se plasma de modo estético. El centro de este diálogo es la herida, la fragilidad, tanto de quienes hospedan como de quienes son hospedados; es decir la fragilidad de la vida que espera ser acogida.

Palabras clave: Arte; Don; Ética; Herida; Hospitalidad; Morada

The Openness to Life as Gift, a Wound and a Home. Dialogues between a Visual Artist and a Moralistic Theologian around Hospitality

- Profesora de Pintura y Dibujo por Escuela Superior de Bellas Artes Regina Pacis. Dicta talleres y clínicas de obra. Participa activamente de exposiciones individuales, colectivas, premios y ferias en Argentina, EEUU, Inglaterra, Colombia, Perú, Brasil, y Suiza. Contacto: www.isabelpenia.blogspot.com

- Licenciada en Teología Moral por la Universidad del Salvador. Profesora de teología en diversas carreras de la Pontificia Universidad Católica Argentina. Miembro del Proyecto de Teólogos Moralistas Argentinos MorAr y del Seminario Permanente de Teología Filosofía Ciencia y Tecnología de la UCA. 
Abstract:

In this article, the voices of a visual artist and a moralist theologian observe hospitality as an opening to life, by setting up a dialogue between theological ethic and aesthetics, through the works of some artists - such as Alejandro Crotto, Hilma Af Klint, Francis Alys, and Isabel Peña herself-. Hospitality that is embodied in theological ethics as a configurating style, rooted in the founding experience of the God who hosts, and in art as a welcome to the vital gift that is embodied in an aesthetic way. The center of this dialogue is the wound, the fragility of both those who host, and those who are hosted; that is to say, the fragility of life waiting to be received.

Keywords: Art; Dwelling; Ethic; Gift; Hospitality; Wound

\section{Consideración inicial}

En este artículo buscamos sintetizar algunas reflexiones en torno a la hospitalidad, nacidas del encuentro vital entre una artista visual, Isabel Peña y una teóloga moralista, Silvina Astigueta. Encuentro dialogal que nos ha permitido, por un lado, observar la hospitalidad como apertura a la vida, como don, como herida y como morada; y por otro, encontrar en la obra de arte y en la tarea creativa del artista, un espacio privilegiado de encarnación de la hospitalidad.

\section{La apertura a la Vida es hospitalidad}

Cuando hablamos de hospitalidad puede venirnos a la mente una puerta abierta, un cuarto de huéspedes, una mesa preparada, lugares acomodados para el que vendrá; y también una palmada en el hombro, una sonrisa franca, una mirada a los ojos, actitudes y gestos de aprecio para el que llega. Hospitalidad es una actitud, es un espacio, es una capacidad.

Pero ¿En qué coinciden estas apreciaciones? La hospitalidad nos sabe a apertura, recibimiento, a disposición, a cobijo y a espacio hecho. Por eso, se parece a una habitación, porque de alguna forma implica habitabilidad, en cuanto a espacio amigable. A su vez, implica morada como lugar de descanso, lugar donde hacer pié, donde reparar las fuerzas. Precisamente, en el arte tanto el artista como 
la obra son lugar habitable cuando dan espacio a lo vital, que queda plasmado como innovación.

¿Pero para quién es esta habitación? ¿A quién está dirigida la hospitalidad? La habitación es para el que llega, el visitante, el que necesita, el extranjero; es decir para la vida de otro que irrumpe o interrumpe, que acude a la medianoche y dice «Amigo" (CF. Lc 11, 5). No importa si es esperado o no, si «te servirá o no, si tiene características que te agradan o no, si responde o no a tus proyectos y a tus sueños». ${ }^{1}$ En este sentido es muy interesante que en arte los indicios de apertura suelen descubrirse como rasgos de singularidad. Si un artista abre su producción a lo inesperado y empuja algún límite establecido, la innovación ocurre. ${ }^{2}$ Por eso aquí tampoco vale decir: «No me molestes; la puerta ya está cerrada» (Lc 11,7). No me incomodes. ${ }^{3}$ La vida del otro o de lo otro se nos presenta igual y con su insistencia nos hace levantar y darle «cuanto necesite» (Lc 11, 8) convirtiéndonos en «hospederos de la vida». ${ }^{4}$ De la que espera ser encontrada, y de la que sale al encuentro conmovida, corriendo y dispuesta a echarse al cuello y besar al que llega (Cf. Lc15, 20). Así, en el encuentro, la vida hospedada se siente apreciada, contemplada, acariciada, sostenida, es decir, dignificada. Le han hecho un lugar, la han colocado en medio de nosotros (Cf. Mt 18,2).

\section{La hospitalidad es don, herida y morada}

La apertura hacia la vida nos habla de algo que en cierta manera es un derecho. La dignidad de las vidas aparecidas, sin importar lo semejante o distintas que sean de nosotros, reclaman

1 Francisco, Amoris Laetitia (19 marzo 2016), 170 (En adelante AL).

2 Se trata de una apertura que puede darse tanto en relación al propio cuerpo de obra del artista, como en relación a la tradición en la que se inscriben sus trabajos.

3 Lo inesperado en el arte también desconcierta y obliga a replantear el statu cuo del artista. Por ejemplo el propio espacio en el taller, en el circuito comercial, en la recepción de la obra que hace el público.

4 Francisco, Homilia con motivo del viaje apostólico a Ecuador, Bolivia y Paraguay Campo Grande ñu guazú (12 julio 2015) (En adelante HCG). 
hospitalidad para sí. Es que no se puede esperar menos que eso. Sobre todo, si se trata de vidas frágiles, carenciadas o, tal vez, rotas. Cuanto más desvalida es esa vida, más «derecho sacro a los cuidados» ${ }^{5}$ y más les «resulta absolutamente obvio recibir cosas buenas». ${ }^{6}$ Por eso solo esperan hospitalidad de nuestra parte ¿Quién se atreve a defraudarlas?

Ahora bien, la hospitalidad como apertura a la vida, excede la categoría de lo debido, o de la obligación. La vida del que viene «tiene, pues, derecho a algo que supera el nivel jurídico y sólo puede satisfacerse como entrega, dedicación y don libres». ${ }^{7}$ Es decir «en el amor». ${ }^{8}$

Así como el que hospeda ofrece un regalo a la vida por ser simplemente ella, también el artista hospeda ese don o vocación que le es regalado, y que lo motiva a trabajar. Al dar su trabajo a otros, el sentido de su obra se multiplica en la diversidad de miradas. Trabaja impulsado por una necesidad profunda, que implica disciplina y disponibilidad a la inspiración. Hace desinteresadamente, por el placer mismo de entregarse, y en el mejor de los casos posibilita el encuentro con la belleza que ocurre, lo sorprende y lo ilumina. Se abre audazmente al diálogo con lo imprevisible. No tendría sentido quedar encerrado, dejando a lo vital fuera de su obra.

Pero nadie puede dar lo que no tiene. ¿Puede ser alguien anfitrión si no ha sido primero huésped?

Esta tarea de hospedar implica haber experimentado el cobijo, la apertura, la caricia o la palmada de quien nos ha recibido en su casa. Alguien habrá vendado primero nuestras heridas. Por eso el don de la hospitalidad nace de la herida, de la conciencia del ser frágil. El anfitrión es un herido que alguna vez fue huésped, antes que eso fue carencia, y ahora cobija gratuitamente otra herida. El anfitrión hospedero no responde desde su fuerza, sino desde su pobreza. Por eso, recibe al huésped diciendo: «no soy digno de que entres en mi

5 Hans Urs Von Balthasar, Si no os hacéis como este niño (Barcelona: Herder, 1989), 28.

6 lbid., 29.

7 lbid., 28

8 lbid. 
casa» (Mt 8, 8) o «¿Quién soy yo para que (...) venga a visitarme?» (Lc 1,43). Porque, de no ser así sería prepotencia y no hospitalidad. El anfitrión da a la vida aparecida un morada herida. Brinda un espacio vacío, un hueco, «un pesebre, porque no tenían sitio» (Lc 1, 7). ${ }^{9}$ Así se hospeda la vida en una herida recibiendo la carencia del otro como don. Recibe una oportunidad de devolver lo recibido, un corazón para abrazar, una tierra sagrada ante la cual descalzarse (Cf. Ex 3,5). Porque el que recibe una vida recibe también un regalo, un nuevo don, por el cual elevar alabanzas, y decir como Maria, «Porque Él miró con bondad la pequeñez de su servidora. En adelante todas las generaciones me llamarán feliz» (Lc 1, 48).

La fragilidad es la puerta de la hospitalidad en donde habita el misterio. Es hacer espacio, abrir las ventanas, prender la luces para que la vida que viene sepa dónde entrar. Desde la conciencia de pobreza, también el artista que ha recibido el don de hacer algo vital, se convierte en morada de inspiración, por medio de un acto de fe. La hospitalidad artística es también convertir un pesebre en morada.

\section{La hospitalidad como ethos}

Ahora bien, la hospitalidad tiene vocación de ser no solo un acontecimiento determinado, un acto aislado, heroico, extraordinario, o una actitud o disposición virtuosa. Como escribe Alejandro Crotto en el poema simone Weil:

\footnotetext{
«Y esforzarse en ser bueno es tan inútil como tratar de levantarse tirándose del pelo para arriba.

Porque la voluntad no opera en el alma ningún bien.

Y sólo en la alegría y el placer puede dar frutos el deseo». ${ }^{10}$
}

9 James Keenan, Virtudes del cristiano (Bilbao: Mensajero, 1999), 142.

10 Alejandro Crotto, «Simone Weil» En: Browning \& Tennyson. Once Personas (Buenos Aires: Bajo La Luna, 2015), 161-162. 
La hospitalidad es más bien un modo de ser y estar, un modo de morar, un modo y estilo de habitar en este planeta para hacerlo menos inhóspito. Es decir una ética o moral. El teólogo moralista López Azpitarte, teniendo en cuenta le etimología, afirma que la ética es «darle a nuestro pathos -ese mundo pasivo y desorganizado que nos ofrece la naturaleza- el estilo y la configuración ( $\rceil \Theta o s)$ querida por nosotros, mediante nuestros actos y formas concretas de actuar $(\varepsilon \Theta o \varsigma) » .{ }^{11}$ Éthos con eta es el estilo configurador de nuestras vidas abiertas a la vida, que se realiza a través del Éthos con épsilon, es decir, los actos concretos y particulares de apertura con los que se lleva a cabo ese estilo-proyecto. El ser humano moldea así creativamente lo que le fue dado para encontrar una orientación, una protección, una ética con la que hacer habitable el mundo. La forma que le dará a esa casa es el estilo, que al igual que el estilo artístico, será único e irrepetible. Pero si quiere ser habitable y amigable, esta morada deberá estar abierta a la vida, deberá ser, como expresa Francisco, «la casa de la hospitalidad». ${ }^{12}$

También A. Crotto percibe la impronta de la morada como estilo en Simone Weil:

\footnotetext{
«Estoy en casa, ahora. Es una casa real, dura, rugosa.

Y también hecha de esta luz pura del alba.

Una patria hermosísima y difícil que debemos amar.

Porque está a cada instante siendo redimida.

Estoy en casa. Ahora debo ser herramienta.

Debo enraizarme toda en la obediencia del vacío.

Dar lugar. Mantener la orientación de la mirada.

Sea mi vida el sarmiento en que la Vida resplandece». ${ }^{13}$
}

Este estilo configurador depende de una experiencia, de un encuentro. Es que quien ha experimentado el dolor de ser extranjero, la fragilidad del pathos, quien a estado a la merced, ha necesitado ser acogido (herida); y se ha sentido recibido, abrazado, protegi-

11 Eduardo López Azpitarte, El nuevo rostro de la moral (Buenos Aires: San Benito, 2003), 34.

12 HCG.

13 Alejandro Crotto, «Simone Weil»... 162. 
do, bendecido (don); ya no puede sino hacer lo mismo con quienes se encuentra a lo largo del camino (tarea).

Dios se nos ha revelado grande en hospitalidad pues «conociendo nuestra vulnerabilidad y sabiendo lo que nos falta... ha sido providente», ${ }^{14}$ se ha hecho cargo de nuestras vidas desarraigadas y sin horizontes (Cf. Ex 3,7; Is 38,5). Jesús mismo se ha convertido en hospedero al asumir carne. Él «acoge en su persona divina nuestra humanidad», ${ }^{15}$ atrae a los hombres, les da un cobijo, una esperanza, un camino, una verdad y una vida (Cf. Jn 14,6). Al final vuelve a la casa del Padre para prepararnos las habitaciones de huéspedes (Cf. Jn 14,2-3).

Como afirma Juan Pablo II, «desde el momento en que el Hijo de Dios "puso su morada entre nosotros", todo hombre, en cierta medida, se ha transformado en el "lugar" del encuentro con Él». ${ }^{16}$ Por lo tanto un estilo configurador conforme a la hospitalidad es, tomando a Francisco, la «cédula de identidad... carta de presentación... credencial» del cristiano. ${ }^{17}$ Porque «lo que tenemos es, en sí mismo, un regalo (...). La hospitalidad es, por tanto, un reconocimiento de lo que se nos ha dado y que podemos dar como regalo». ${ }^{18}$ Por eso, «nada puede reportarnos más placer» que «la práctica divina de cuidar la humanidad». ${ }^{19}$

Esta forma de morar, este estilo ético, se contrapone a otros estilos; uno construye moradas habitables, otros desiertos y soledades. ${ }^{20}$ Se trata de la lucha entre la «cultura de la vida» ${ }^{21}$ que es «cultura de la hospitalidad» ${ }^{22} \mathrm{y}$ «cultura de la acogida», ${ }^{23}$ y la «cultura

14 James Keenan, Virtudes del cristiano... 145.

15 Juan Pablo II, Discurso a los voluntarios italianos de la Hospitalité Notre Dame de Lourdes y a un coro de Boston (8 marzo1997), 2.

16 Juan Pablo II, Homilia con motivo del Jubileo de los Emigrantes e Itinerantes (2 junio 2000), 2

17 HCG.

18 James Keenan, Virtudes del cristiano... 143.

19 lbid., 145.

$20 \mathrm{Cf}$. Benedicto XVI, Homilia en el solemne inicio del ministerio petrino (24 abril 2005) y HCG.

21 Juan Pablo II, Evangelium Vitae (25 marzo 1995), 6. [En adelante EV]

22 Juan Pablo II, Discurso a los voluntarios italianos... 2.

23 Juan Pablo II, Homilia con motivo del Jubileo... 3. 
de la muerte» ${ }^{24}$ o «cultura del descarte». ${ }^{25}$ Dos modelos, «dos maneras de afrontar la vida y de afrontar la misión ${ }^{26}$ con dos lógicas diferentes. Así nos lo enseña Francisco, una es la lógica del egoísmo, de la clausura, de la lucha, de la división, de la superioridad, del dominio, del aplastar y manipular; la otra es la lógica de la vida, de la gratuidad, del amor, del acoger recibir y cuidar. La ética de la hospitalidad como apertura a la vida nos conduce a «un horizonte lleno... de belleza, de verdad, de plenitud», ${ }^{27}$ es decir: de Evangelio.

Ante "tanta "miseria inmerecida" ${ }^{28}$ la ética de la hospitalidad mira a todos los hermanos que necesitan cuidado y además a la hermana tierra; ella también clama por una estilo de vida abierto a la vida, respetuosa de «de los ritmos inscritos en la naturaleza por la mano del Creador». ${ }^{29}$ Necesitamos volver a morar en el mundo como si fuéramos huéspedes y no propietarios, como hermanos pequeños no «como dueños».30 La ética de la hospitalidad implica aprender a «alojar como la tierra, que no domina la semilla, sino que la recibe, la nutre y la germina». «Alojar como María, que no dominó ni se adueñó de la Palabra de Dios sino que, por el contrario, la hospedó, la gestó, y la entregó». ${ }^{31} \mathrm{Y}$ también, alojar como el arte.

\section{El arte como morada}

Este estilo configurador, que es un don y una tarea para todos, tiene sin duda, un hábitat propicio en el arte. Principalmente porque el arte tiene esa capacidad de ser morada de algo vital. El que hace arte, acoge a lo desconocido y con sus propios recursos, lo ofrece al mundo. En él hay un movimiento vertiginoso por albergar

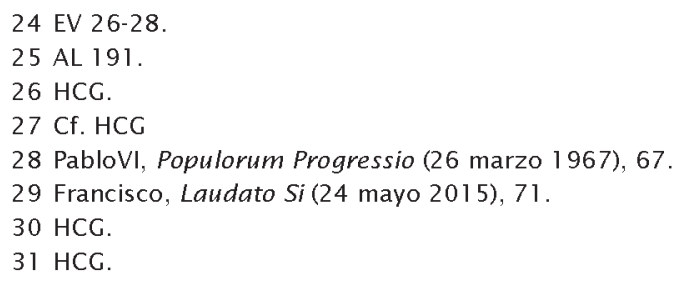


lo invisible, lo imaginado, lo novedoso, que toma una forma singular. Esta singularidad finalmente será volcada para ser hospedada por la percepción de otros.

El artista cuenta con una amplia paleta de disciplinas y posibilidades del lenguaje y sus mixturas, para manifestar algo de la dimensión espiritual, de lo vital, de lo originario. Pero siempre en la medida en que se deje habitar por el ethos de la hospitalidad, que implica abrir el espacio de la libertad de creación al don. El arte que hospeda a la vida es el que ha tenido el privilegio de experimentar la espiritualidad que constituye a su trabajo. Así el artista se transforma en anfitrión de lo inesperado. La obra es acción en gratitud, hospeda al amor que desborda de la fuente, de la verdad no dicha. Como lo expresa Crotto en Simone Weill.

«Porque esto quiso su ávida bondad: marcarme suya.
Y lo hizo emboscándose un verano de mi infancia
en los fresnos, filtrándose en el viento de las hojas,
susurrando su música imposible y verdadera
en mis pobres oídos, seduciéndome, tendiéndome
la trampa en que quería que cayera. Y yo caí (...)». ${ }^{32}$

Por el contrario, si no se deja habitar se convierte en un operario que produce imágenes o cosas que no conmueven, ni abren preguntas, ni interpelan al otro a detenerse y darle lugar. Se usan como nacieron: para ser usadas. Si tocan al hombre, lo hacen superficialmente, en el orden de lo comercial, homogeneizando todas las voces en un inhóspito sistema de solistas que compiten entre sí.

En cambio, un sistema abierto a la vida genera un coro polifónico. Muchos artistas se dejan habitar por el don y se transforman en habitaciones para otros. Así como Isabel respondió a lo inesperado y expresó en poemas la visita de María, como si fuera un derrame colateral de alegría. Así como a Zacarías le costó 
creer, quedó mudo, introspectivo, y luego recuperó su voz; los artistas también están disponibles ante la maravilla. Ellos también tienen bloqueos creativos, retoman su trabajo a pesar de sus fallas o desconciertos, y atraviesan abanicos de sentimientos ante lo inabarcable.

Entre ellos, por ejemplo la pintora de vanguardia y pionera de la abstracción, Hilma Af Klint. Una artista de principios del siglo que $X X$ que supo que su obra sería para el futuro. ${ }^{33}$

En sus obras vemos apertura a la vida de audacia inusitada. Integra contenidos espirituales, biomórficos y psicológicos, (lleno de símbolos, colores saturados pero armónicos, letras y palabras), que son íntimamente coherentes con la forma. Su éxito internacional, 80 años después de su muerte, abre preguntas sobre la sed de belleza de la sociedad actual.

La artista participó de reuniones espirituales religiosas, trabajando algunos años en base a sesiones mediúmnicas, guiada por entidades espirituales. Su pintura es precursora no solamente de la abstracción, sino de aspectos ocultos en la naturaleza, lo espiritual, $\mathrm{y}$ otras dimensiones por entonces invisibles.

Innovó en el uso del automatismo, más de una década antes de que surgiera el surrealismo; y reveló imágenes de hallazgos de electromagnética y biología antes de que fueran difundidos por la ciencia. A través de su entrega a la pintura, nos rendimos ante el movimiento de profunda integración que experimenta cada ser humano que contempla la belleza de su obra.

33 Hilma Af Klint propuso que se postergara su presentación 20 años después de su muerte, auque finalmente llevó 42. Es paradigmático que una obra hecha a principios del s XX trascienda hoy con semejante potencia; sobre todo en un contexto de tanta fragmentación, distracción y aceleración. 


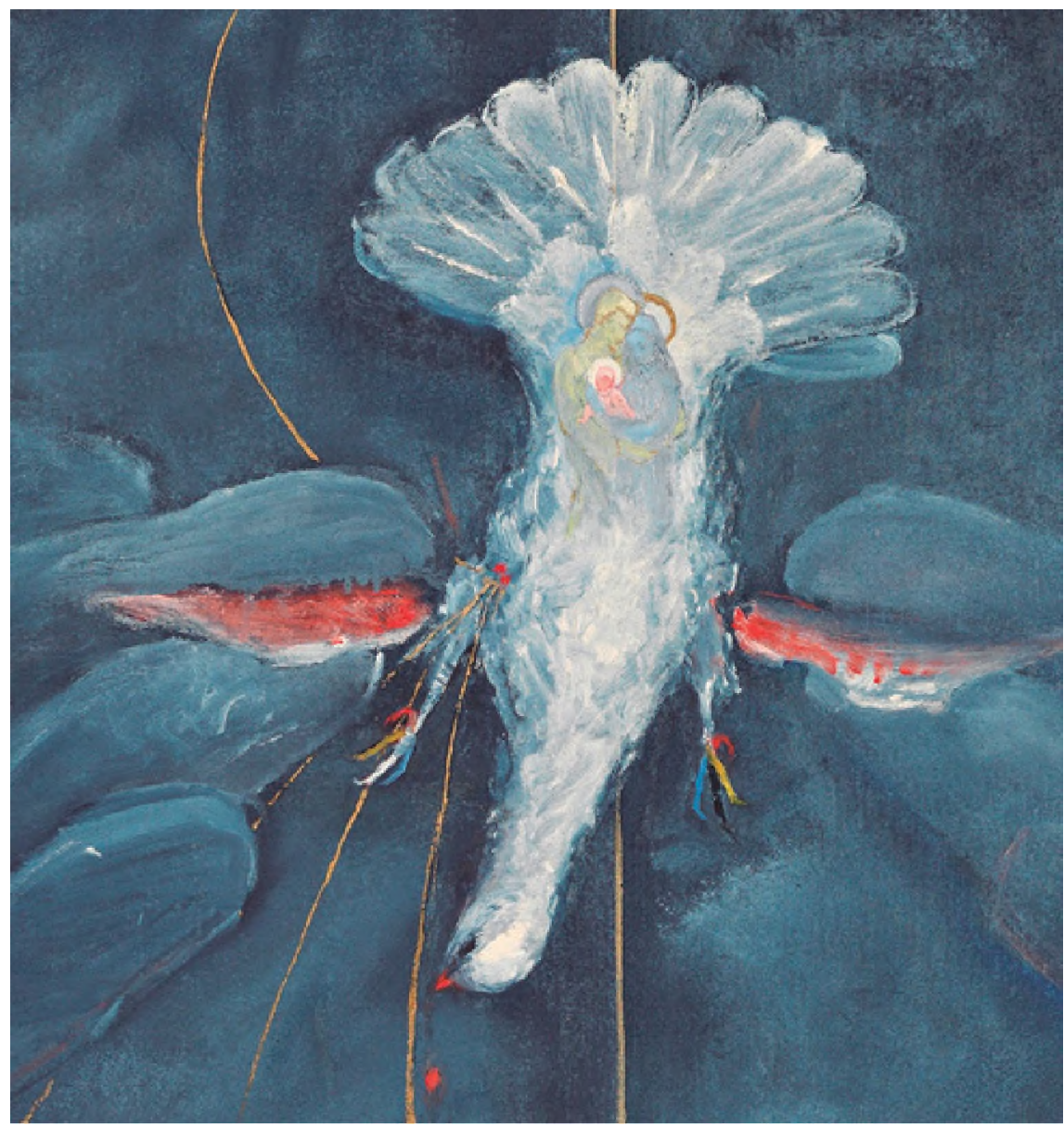

Detalle. Af Klint, Hilma, Group IX/UW, No. 29. The Dove, No. 5, 1915, óleo sobre tela $152.5 \times 117.5 \mathrm{~cm}$. Cortesía de Hilma af Klint Foundation.

En The Dove, No.5 (1915), Af Klint representa un soplo o aleteo de la Santísima Trinidad que siembra con proporción aúrea (el número de oro que da armonía, pintado en líneas doradas) campos o un mar geométrico de trigo.

Observamos una representación polisémica de: a) peces, que también se ven como b) alas de la paloma y c) viento representado por d) manos enormes que se transparentan en el cielo o cosmos y que impulsan o sostienen a la paloma. Lo que podríamos percibir 
como una síntesis del don en movimiento. Es acaso también una representación del Hijo en la Sagrada Familia que está escondida pintada en los colores primarios en el interior de la paloma (El Espíritu Santo), cuyas alas son movidas por las manos de Dios Padre.

Otro ejemplo puede ser Francis Alÿs, quien ejerce y recibe la hospitalidad, en su forma de trabajar y en los temas que elige, sobretodo en torno a la problemática de las migraciones. Él realiza performances, videos, pinturas, residencias y acciones poéticas colectivas en lugares con riesgo bélico. Elabora sus trabajos en base a situaciones vinculadas a la forma en la que se viven situaciones traumáticas, de pérdida o con tensiones políticas graves. Como artista nómade, visita contextos y elabora sus propias respuestas trabajando en general con los juegos de los niños. Él sale al encuentro y es recibido. Conoce a las personas, pinta, escribe, boceta, y da forma a cada proyecto considerando cuatro patas fundamentales para su trabajo: la poética, la política, la estética y la ética.

Alÿs, Francis, 2008. Estudio para En una situación dada. 
En su obra No cruzarás el río antes de llegar al puente, Alȳs genera una acción performática protagonizada por niños de ambos lados del Estrecho de Gibraltar. Hace una apropiación del juego infantil de ese contexto específico, para jugar con ellos a cruzar el mar caminando. Filma la utopía con actores-habitantes reales de ambos lados del Estrecho. El indicio de las diferencias entre una costa y la otra es dado en el video por el sonido. Dos idiomas que con sus niños, juegan a lo mismo, a generar un puente. Luego exhibe este trabajo, usando bocetos, textos, y los juguetes mismos, en instalaciones, junto al video en gran escala. ${ }^{34}$

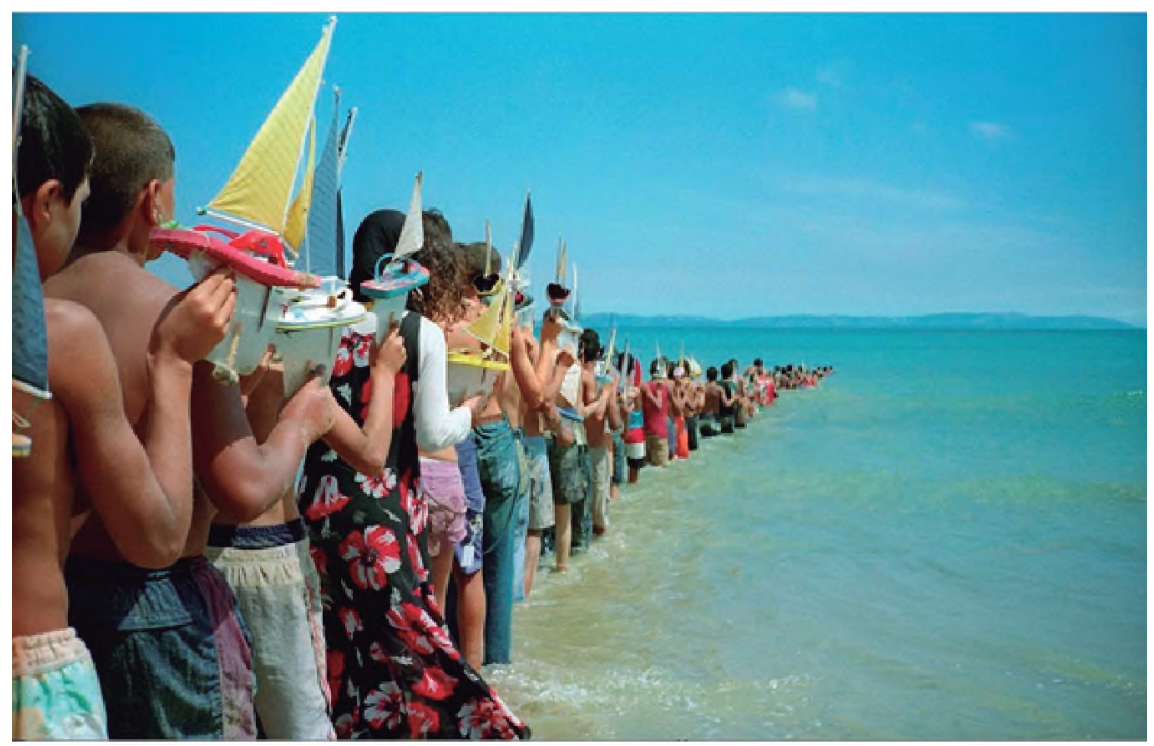

Alÿs, Francis, 2008. No cruzarás el río antes de llegar al puente, Estrecho de Gibraltar, Marruecos, documentación fotográfica de una acción. Video: https: / / www.youtube.com/watch?v=4qg7Bhgf1-k

También Isabel Peña quiere ser morada, intenta ser receptiva al don y servir a la gracia. Atravesando aprendizajes y oscuridades, se hace cargo y transmuta sus pasiones en la obra. Sus trabajos en sitio específico ( $\mathrm{y}$ en las pinturas que de esa serie derivaron), son obras re- 
lacionales. A través de estos trabajos, busca reactivar las miradas hacia trabajadores que habitan 'no lugares', muchas veces de alto tránsito. Estas obras realizadas entre el 2005 y el 2010, reactivan espacios muertos, como ser puertas, espejos o ventanas en espacios públicos (shoppings, hoteles y galerías de arte). Así es desde la perspectiva de Isabel:

«Los demás somos todos visitantes. Quería dejar huellas de esa forma de estar, haciendo retratos como ecos de esas presencias reales. Los retratados, son los menos visibles por estar constantemente presentes: guardias de seguridad, operarios de mantenimiento, etc.». ${ }^{35}$

Por ejemplo, en Esquina2 (2006), realizada para el X Premio Klemm, Isabel realizó una búsqueda del tesoro sin epígrafes, instalando cajas de luz que señalaban a guardias de seguridad del lugar.

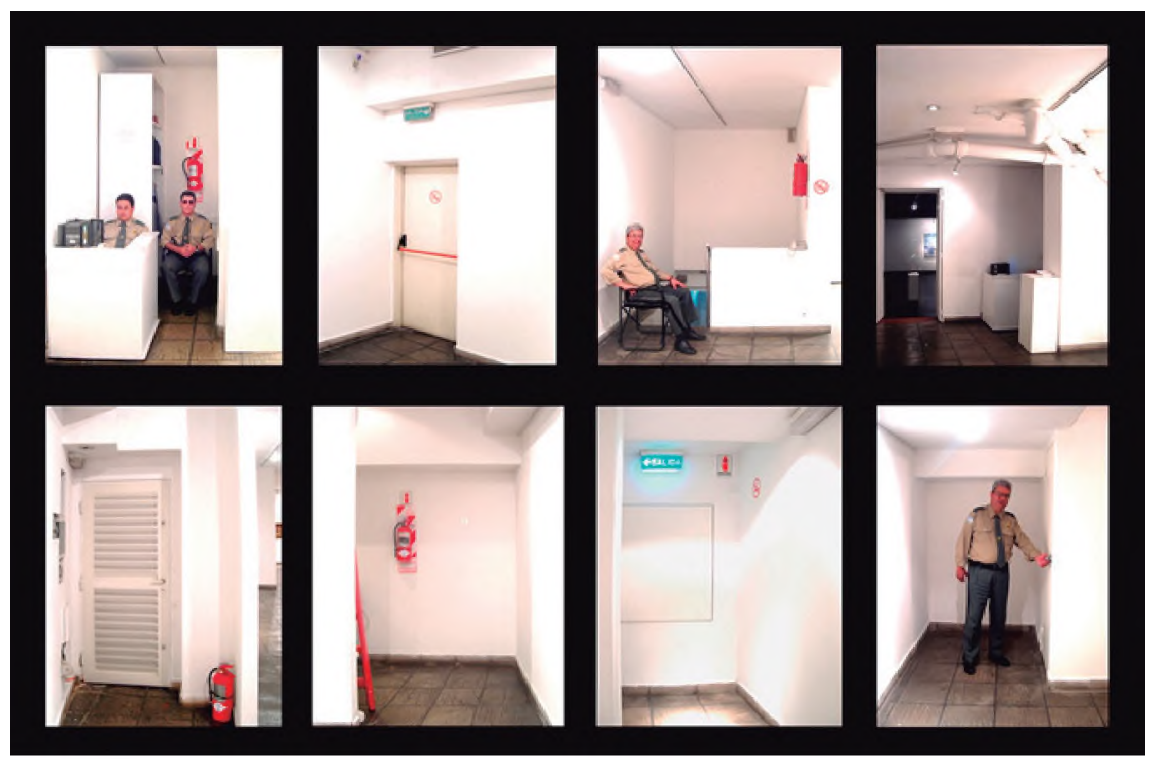

Peña, Isabel, Esquina2, 2006, Instalación X Premio Klemm Artes Visuales, Fundación F. Klemm, Buenos Aires. Siete fotos en cajas de luz de 40 × 30 x 15 cm.

35 Isabel Peña (artista visual) en conversación con la artista, marzo-abril de 2019. 
«Fui al espacio con la idea de descubrir paredes sobre las que pintar, pero al escuchar (en el silencio de la galería) la voz de los guardias, les pedí permiso y tomé estas fotos. Luego al hacer la instalación, la gente jugaba a descubrir el recorrido de 7 cajas repartidas por el espacio. Era como duplicar esas presencias humanas, vivas, con algo de humor por su constancia». ${ }^{36}$

En Sites Pacific, Peña instaló fotos retratando situaciones cotidianas de trabajadores en espacios muertos y puertas de un hotel para un Premio site-specific.

«Adapté la escala de las fotos de una manera escenográfica, llevando los retratos a tamaño natural. Como si fueran trompe l'oeil, jugué con la luz de ese espacio y con puntos de vista reales, como si estas personas estuvieran ahí, en puertas o ventanas corridas de lugar, abriendo espacios dislocados».

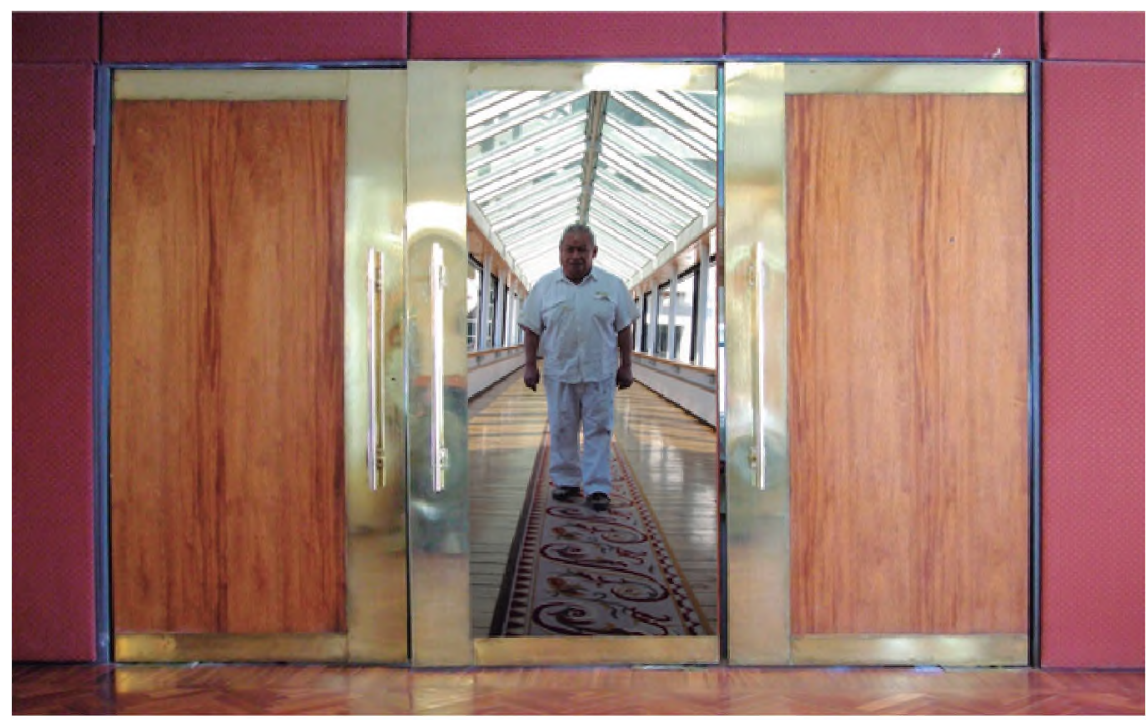

Peña, Isabel, SiteS-Pacific, 2008, instalación

Premio Panamericano Proyecto Site-specific, Hotel Panamericano de Bariloche.

Otro ejemplo podría ser la Pintura site-specific realizada en 2011 para el Hospital Tornu. La obra se llamó Entre tanto..., intentando aludir a ese intersticio de dificultad de ser pacientes. 
«En otra ocasión, pinté una foto de mi propio cuerpo en un momento de fragilidad, con una pierna rota. La hice para ser instalada en una vitrina en la sala de espera del Hospital Tornú, en una escala algo mayor a la natural. Un perro fiel descansaba debajo en esa imagen, como sabiendo estar echado». ${ }^{37}$
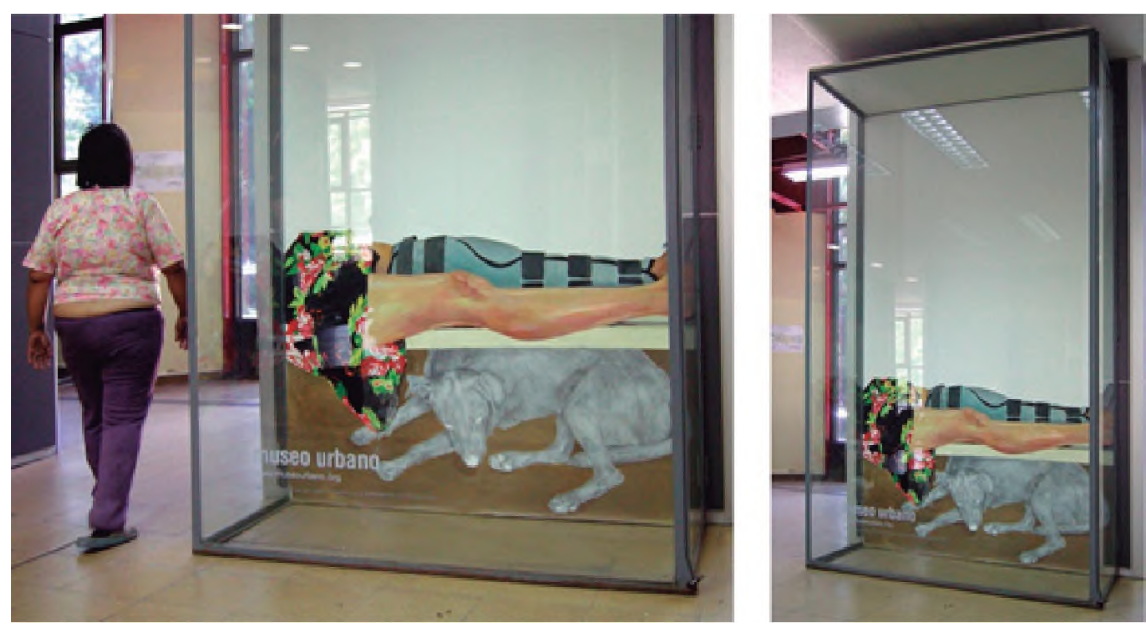

Entre tanto, Peña, Isabel 2011. Pintura sobre tela y madera $153 \times 220 \mathrm{~cm}$, en Hospital Tornu.

Sin duda estos tres artistas, tan distintos entre sí, tienen un denominador común, ellos están abiertos al Otro y a los otros, otras vidas. Son conscientes que sin esta apertura la obra no puede ser habitada y, entonces, pierde sentido. Si al artista le falta libertad y se somete a modas herméticas o a reglas ajenas, la audiencia se queda afuera, porque le es inhóspita. Por eso estos artistas trabajan desde la espiritualidad de apertura, cuando aceptan ser canales de ese "Otro" fuente de Belleza.

Así nos lo transmite Peña

«Los que co-creamos en este mundo, damos cuenta de nuestra condición de creaturas, y la experimentamos cotidianamente. La inocencia, en ese sentido, da placer y alegría, lo lúdico, invita al juego del hallazgo, a estar en el

37 Ibid. 
momento presente y a la convivencia con el vértigo del misterio. No significa que sea siempre un camino amable o fácil; pero la luz se cuela igual». ${ }^{38}$

\section{Consideración final}

Terminamos haciéndonos eco de las palabras de Hugo Mujica: «La creación es el don de la creación: Lo que se nos da sin ser, lo que busca sernos. Su acogida es lo creado, Lo creamos siéndolo. Lo somos creándolo. Acogiéndola nos crea». ${ }^{39}$ La hospitalidad se nos manifiesta, así, como una vocación a recibir vitalmente el don de la vida frágil, dentro del hueco de nuestra propia fragilidad.

\section{Bibliografía}

Avenatti de Palumbo, Cecilia. «La hospitalidad como poética de la esperanza» Franciscanum 168, Vol 168 (2017): 175-196. https:/ / revistas.usb.edu.co/index.php/Franciscanum/article/view/3400/2812

Benedicto XVI, Homilia en el solemne inicio del ministerio petrino. Roma, 24 de abril 2005. http://www.vatican.va/content/ benedict-xvi/es/homilies/2005/documents/hf_ben-xvi_ hom_20050424_inizio-pontificato.html

Crotto, Alejandro, «Simone Weil» En: Browning \& Tennyson. Once Personas. Buenos Aires: Bajo La Luna, 2015, 159-162.

Francisco, Amoris Laetitia. Roma, 19 de marzo 2016. http://www. vatican.va/content/francesco/es/apost_exhortations/documents/papa-francesco_esortazione-ap_20160319_amoris-laetitia.html 
Francisco, Homilía en Campo Grande Ñu Guazú. Asunción, 12 de julio 2015. http://www.vatican.va/content/francesco/es/homilies/2015/documents/papa-francesco_20150712_paraguay -omelia-nu-guazu.html

Francisco, Laudato Si. Roma, 24 de mayo 2015. http://w2.vatican. $\mathrm{va/content/francesco/es/encyclicals/documents/papa-}$ francesco_20150524_enciclica-laudato-si.html

Juan Pablo II, Discurso a los voluntarios italianos de la Hospitalité Notre Dame de Lourdes y a un coro de Boston. Roma, 8 de marzo 1997. http://w2.vatican.va/content/john-paul-ii/es/speeches/1997/march/documents/hf_jp-ii_spe_19970308_volontari-membri.html

Juan Pablo II, Evangelium Vitae. Roma, 2 de Junio 2000. http:// w2.vatican.va/content/john-paul-ii/es/encyclicals/documents/hf_jp-ii_enc_25031995_evangelium-vitae.html

Juan Pablo II, Homilía con motivo del Jubileo de los Emigrantes e Itinerantes. Roma, 2 de Junio 2000 http://w2.vatican.va/content/john-paul-ii/es/homilies/2000/documents/hf_jp-ii_ hom_20000602_jubilmigrants.html

Keenan, James, Virtudes del cristiano. Bilbao: Mensajero, 1999.

López Azpitarte, Eduardo, El nuevo rostro de la moral. Buenos Aires: San Benito, 2003.

Mujica, Hugo, Dionisio Eros creador y mística pagana. Buenos Aires: El hilo de Ariadna, 2016.

Pablo VI, Populorum Progressio. Roma, 26 de marzo 1967. http:/ / www.vatican.va/content/paul-vi/es/encyclicals/documents/hf_p-vi_enc_26031967_populorum.html

Potente, Antonieta, Un bene fragile. Riflessioni sull'etica. Italia: Mondadori, 2013.

Von Balthasar, Hans Urs, Si no os hacéis como este niño. Barcelona: Herder, 1989. 


\title{
Hospedar la diversidad
}

\section{Lo que Jesús hace con todas las personas}

\author{
Andrea Sánchez Ruiz• \\ Universidad de San Isidro Dr. Plácido Marín \\ Buenos Aires, Argentina \\ andreasrw@hotmail.com \\ Recibido 16.11.2020/ Aprobado 20.02.2021 \\ DOI: https://doi.org/10.46553/teo.58.134.2021.p109-132
}

\section{RESUMEN:}

Cabría pensar que en el ámbito familiar la hospitalidad supone hacer del propio hogar una morada a quien adviene de fuera, desconocido o forastero y es recibido para augurar un fecundo "nosotros». Sin embargo, a lo largo de la trayectoria familiar, no solo reconocemos en el hijo o la hija que llega, recién nacido o ya crecido, indefenso, necesitado, un tú a quien hospedar amorosamente sino también a quien va ir siendo con el paso de los años. Y ese ser que va siendo, en su entera libertad, también habrá de ser hospedado más de una vez si se muestra, por momentos, como un extraño a quien abrir las puertas para seguir siendo «nosotros» siendo cada uno, cada una, sí mismo.

En estas páginas, a partir de la experiencia de hospedarse/ hospedarnos en familia, haré foco en la situación que se plantea cuando un niño o una niña se manifiesta como transgénero. No abordaré una temática. No estudiaré un objeto: la transexualidad. No abriré juicios morales. La complejidad de la situación demanda una reflexión teológica y antropológica que no será en esta ocasión más que un balbuceo, preguntas que nos interpelen a pensar cómo Dios se revela en tales circunstancias, cuál es su Rostro en sus rostros, qué antropología podemos imaginar para incluir identidades que desbordan los límites de lo conocido y aprendido.

Siguiendo a Rita Segato, plantearé brevemente mi abordaje como una «antropología por demanda», para ofrecer las lentes desde donde podré enfocar la experiencia de

- Licenciada en Teología con especialización en Teología Dogmática por la Universidad Católica Argentina. Se especializó en Psicoanálisis y Género y tiene una diplomatura en Pastoral familiar. Docente en diversas instituciones educativas. 
vida narrada por los papás y las mamás que han recorrido este camino con sus hijos e hijas. En un segundo momento aclararé algunos conceptos básicos que nos permitan una comprensión más amplia de lo que iremos reflexionando. Finalmente, la llamada insistente del Evangelio, que en palabras de Francisco nos interpelan a aceptar y promover, «el desafío de la hospitalidad, la cultura del encuentro», nos ofrecerá el camino para un abordaje teológico y antropológico en proceso y, por tanto, inacabado.

Palabras clave: Antropología teológica; Hospitalidad; Diversidad; Sexualidad; Transexualidad

\section{Embrace Diversity. What Jesus does with Everyone.}

ABsTRACT:

It is easy to think that within the family nucleus hospitality means offering our own home to any stranger and welcome him to a future «we». However, throughout our family history, the daughter or son who is coming, whether a newborn or a grown up, is a person to lovingly took care of and host over the years. This free human being will be also taken in several times if he/she shows himself/ herself as a stranger to other people with whom later become a «we».

Throughout these pages, based on the experience of living as a family, I will concentrate on the situation that arises when a child identifies himself/herself as transgender. I will not address one topic. I will not study an object: transsexuality. I will not introduce moral judgments. The complexity of the situation requests a theological and anthropological debate but in this case it will only be a summary to leave space to questions about how God reveals himself in this situations, to see his face in our face and to image an anthropology in which we can include the different identities beyond the scope of what we already know.

Following Rita Segato, I will briefly present my own approach about «anthropology by demand», to shine a light on the life experience narrated by the parents that have come a long way with their children. Secondly, I will clarify some basic concepts for a broader understanding. Finally, the constant call of the Gospel, as expressed by Francisco when he talks about accepting and supporting «the challenge of hospitality, culture and gather ing» will leads us the way towards the ongoing theological and anthropological approach, which is still unfinished.

Keywords: Theological anthropology; Hospitality; Diversity; Sexuality; Transsexuality

Cabría pensar que en el ámbito familiar la hospitalidad supone hacer del propio hogar una morada a quien adviene de fuera, desconocido o forastero y es recibido para augurar un fecundo «nosotros». Sin embargo a lo largo de la trayectoria familiar, no solo reconocemos en el hijo o la hija ${ }^{1}$ que llega, recién nacido o ya crecido,

1 Como todavía no existe un acuerdo entre lingüistas acerca del modo en que se puede resolver el uso de un lenguaje no sexista y con el fin de evitar la sobrecarga que supondría marcar 
indefenso, necesitado, un tú a quien hospedar amorosamente sino también a quien va ir siendo con el paso de los años. Y ese ser que va siendo, en su entera libertad, también habrá de ser hospedado más de una vez si se muestra, por momentos, como un extraño a quien abrir las puertas para seguir siendo «nosotros» siendo cada uno, cada una, sí mismo.

En estas páginas, a partir de la experiencia de hospedarse/ hospedarnos en familia, haré foco en la situación que se plantea cuando un niño o una niña se manifiesta como transgénero. ${ }^{2}$ No abordaré una temática. No estudiaré un objeto: la transexualidad. ${ }^{3}$ No abriré juicios morales. La complejidad de la situación demanda una reflexión teoantropológica que no será en esta ocasión más que un balbuceo, preguntas que nos interpelen a pensar cómo Dios se revela en tales circunstancias, cuál es su Rostro en sus rostros, qué antropología podemos imaginar para incluir identidades que desbordan los límites de lo conocido y aprendido, antropologías interpelantes, al servicio de la comunión.

Siguiendo a Rita Segato, plantearé brevemente mi abordaje como una «antropología por demanda»," para ofrecer las lentes desde

léxicamente la diferencia genérica, en este trabajo cuando se utilice solo el género masculino se incluye a toda persona humana, a excepción de aquellos casos en que se refiera solo a varones.

2 Transgénero, incluye a todas aquellas personas que de modo diverso encarnan formas de vida no reducibles al binarismo sexual. Cf. Susana Gamba, Diccionario de estudios de género $y$ feminismos, s.v. "Transgénero».

3 El Nuevo Diccionario de Teología Moral define la transexualidad «como el fenómeno por el cual un sujeto se vive como perteneciente al sexo opuesto al que biológicamente pertenece, con el consiguiente deseo de la transformación anatómica de su cuerpo". Francesco Compagnoni et al., Nuevo diccionario de teología moral, s.v. "Homosexualidad y transexualidad». Excede el objetivo de este trabajo examinar las tensiones lingüísticas que atraviesan los términos transgénero, transexualidad, identidades trans. Cf. R. Lucas Platero, Trans"exualidades, acompañamiento, factores de salud y recursos educativos, (Barcelona: Bellaterra, 2014). Aingeru Mayor, Tránsitos, (Barcelona: Bellaterra, 2020). Así como recoger las diversas hipótesis acerca de la etiología de la transexualidad. Cf. Iván Aragno, Sexualidad humana, (México D.F.: Manual Moderno, 2008), capítulo 8; Javier Gómez, Psicología de la sexualidad, (Madrid: Alianza, 2018), capítulo 3; Spencer Rathus, Jeffrey Nevid, Lois Fichner, Sexualidad humana (Madrid: Pearson Educación, 20056), capítulo 5; Janet Shibley, John DeLamater, Sexualidad humana (México: Mc Graw-Hill, 200399), capítulo 14.

4 Rita Segato, Contra-pedagogía de la crueldad (Buenos Aires: Prometeo, 2018), 32. En cursiva en el original. También en: Rita Segato, La crítica de la coloniedad en ocho ensayos, (Buenos Aires: Prometeo, 2013), 12. Para Segato, esta antropología por demanda produce conocimientos y reflexiones como respuesta a las preguntas que le son hechas por quienes en una perspectiva clásica serían sus «objetos» de estudio. Cf. Segato, La crítica... 70. 
donde podré enfocar la experiencia de vida narrada por los papás y las mamás que han recorrido este camino con sus hijos e hijas. En un segundo momento aclararé algunos conceptos básicos que nos permitan una comprensión más amplia de lo que iremos reflexionando. Finalmente, la llamada insistente del Evangelio, que en palabras de Francisco nos interpelan a aceptar y promover, «el desafío de la hospitalidad, la cultura del encuentro», ${ }^{5}$ nos ofrecerá el camino para un abordaje teológico y antropológico en proceso y por tanto, inacabado.

\section{La realidad nos demanda}

Acompañando docentes, equipos de conducción y de orientación escolar, representantes legales, como miembro del equipo de Educación para el Amor de la Junta Regional de Educación Católica en la implementación de la ley de Educación Sexual Integral, ${ }^{6}$ tuve la ocasión de conocer a una familia que, como otras, transitó (y transita) la experiencia de ir descubriendo en los gestos y palabras de su hija, la firme convicción de sentirse transgénero (aunque ella solo diga de sí misma que es una niña). Su testimonio me conmovió profundamente y sigue interpelando mis propias convicciones, $\mathrm{mi}$ reflexión antropológica y teológica y mi actuar cotidiano. ${ }^{7}$ En nuestras conversaciones solían preguntarme acerca de las enseñanzas de la Iglesia acerca de la situación que atravesaban, ya que siendo su hija alumna de una Institución católica querían acompañarla in-

5 Francisco, 41 Encuentro de Jóvenes de la comunidad de Taizé, acceso 15 de enero de 2019 , http://www.ansalatina.com/americalatina/noticia/papa_vaticano/2018/12/28/mensaje-de-inclusion-a-jovenes-ecumenicos-de-taize_c7d916bc-c662-4f65-a649-1f426e756ba0.html. En este mensaje para el 41 Encuentro de Jóvenes de la comunidad ecuménica Taizé, el Papa Francisco les pidió a 15 mil asistentes, reunidos en Madrid del 28 de diciembre de 2018 al 1 de enero de 2019 , «hacerse prójimos de esta humanidad herida y de aquellos que son expuestos al descarte, rechazados y excluidos, pequeños y pobres».

6 Ley 26150/2006, del Programa Nacional De Educación Sexual Integral, acceso el 26 de enero de 2019, https://www.buenosaires.gob.ar/sites/gcaba/files/ley2110.pdf.

7 No solo recogido en los encuentros que mantenemos sino también grabado con ocasión de una presentación acerca de la temática a los representantes legales de colegios católicos el día 6 de noviembre de 2018. 
tegrando también los saberes que le fueran transmitiendo desde la catequesis. Como ellos muchas familias que hospedan en sus vidas a una persona transgénero y quienes atraviesan en carne propia la situación, también se interrogan sobre lo que la Iglesia puede enseñarles acerca de la experiencia que transitan y desean sentirse recibidos como son, sin cuestionamientos acerca de su identidad. ${ }^{8}$

A la vez, en un encuentro para directivos y representantes legales de colegios católicos, tuvimos la ocasión de dialogar sobre las nuevas expresiones de la sexualidad que se viven cotidianamente en las escuelas y los desafíos que generan. Las personas asistentes estaban de acuerdo en que el Evangelio de Jesús nos exige siempre una actitud de cercanía, inclusión y valoración de todas las personas en la situación en que se encuentren. Pero al mismo tiempo solicitaban, de parte de la reflexión teológica, una palabra que ofreciera fundamentos antropológicos para comprender esas realidades congruentes con la palabra de Dios y de la larga tradición eclesial que la ha interpretado.

Interpelada por estas voces, encontré en la reflexión de la antropóloga argentina Rita Segato, una propuesta inspiradora para trabajar, escuchando primero las preguntas que nos llegan para luego buscar posibles abordajes teóricos a las demandas que se plantean en torno a esta realidad. Segato, presentando su itinerario como antropóloga y docente de la Universidad de Brasilia, recuerda que recibió alrededor de los años 90 una convocatoria junto a otras colegas para responder una pregunta de la Secretaría de Seguridad Pública sobre la violencia en Brasilia hacia las mujeres. «Esa y otras solicitudes que siguieron a lo largo de los años me llevaron a utilizar la expresión «antropología por demanda». ${ }^{9}$ Con ello se refiere tanto a responder una demanda como solicitación, como a participar

8 En varias ocasiones fui testigo de estos planteos y de la dificultad que entrañan, por no «encajar» (textual) en la antropología que enseña la Iglesia. Cf. Congregación para la Educación Católica, Varón y mujer los creó (Ciudad del Vaticano, 2019) edición en PDF, 11, 14 y 24. En adelante VM y el número correspondiente. Ver también Conferencia Episcopal Argentina, El Dios de la vida y del amor humano (Buenos Aires: CEA Oficina del libro, 2019), 6, 14-15.

9 Segato, Contra-pedagogía...32. 
en las reivindicaciones que surjan no ya de quienes son objetos de estudio, sino de quienes «interpelan a la antropología, emparentada vocacionalmente con el campo de la justicia». ${ }^{10}$ Propone así una inversión del orden consabido, por cuanto supone hacernos disponibles frente al rostro del otro escuchando las preguntas que nos llegan, en lugar de responder con discursos elaborados a priori, lo que suponemos acerca de quienes interrogan. En este sentido la escucha cuestiona y hasta puede erosionar las certezas propias y ajenas. ${ }^{11}$ Segato afirma con agudeza que solo abriéndonos a la incomodidad del otro, con sus diferencias y demandas, será posible, en ese gesto hospitalario y acogedor, expandir su inteligencia, su capacidad de comprensión del sentido de la vida, ${ }^{12}$ realizando una reflexión antropológica «atenta e interpelada por lo que esos sujetos nos solicitan como conocimiento válido que pueda servirles para acceder a un bienestar mayor».13

Esta apertura a incorporar la demanda de quienes interpelan con sus vidas al discurso teórico, asumida deliberadamente en la reflexión antropológica de Segato, resulta motivadora también para la reflexión de la antropología teológica. ¿Hasta qué punto nos dejamos interpelar por las vidas sufrientes de quienes no encuentran su lugar en las afirmaciones transmitidas por siglos acerca de la sexualidad humana en la Iglesia católica? ¿De qué nos hablan aquellos cuerpos que luchan por ser nombrados sin ambigüedades ni sospechas? ¿Cómo habríamos de escuchar las historias de vida de quienes han ido descubriendo en su biografía que su identidad sexual no es coincidente con el sexo consignado al nacer para que nuestros discursos se vean interpelados? ¿Qué puede ofrecer la reflexión teológica como orientación vital para quienes quieren seguir a Jesús, allí donde se encuentran?

10 Segato, La crítica...14. Cf. Segato, Contra pedagogía...33.

11 lbid., 38.

12 lbid., 35

13 Segato, La crítica...13. 
Si bien son cada vez más frecuentes los discursos antropológicos anclados en la situación contemporánea y no tanto en «especulaciones abstractas que ignoran la materialidad humana», ${ }_{14}^{4}$ sigue vigente un pensamiento que ante los desafíos del tiempo presente no siempre es capaz de pensar y proponer un mensaje encarnado. ${ }^{15}$

El documento de la Congregación para la Educación Católica, Varón y Mujer los creó, que promueve una metodología articulada en tres actitudes, escuchar, razonar y proponer para favorecer el encuentro con las necesidades de las personas y las comunidades; señala en los números introductorios que

«en el sexo radican las notas características que constituyen a las personas como hombres y mujeres en el plano biológico, psicológico y espiritual, teniendo así mucha parte en su evolución individual y en su inserción en la sociedad. En el proceso de crecimiento esta diversidad, aneja a la complementariedad de los dos sexos, responde cumplidamente al diseño de Dios en la vocación enderezada a cada uno». ${ }^{16}$

De acuerdo con estas afirmaciones, habiendo escuchado las demandas de las personas transgénero y de sus familias, surgen algunos cuestionamientos. Si el diseño de Dios en la vocación personal se realiza en la diferencia complementaria de los sexos que constituyen a varones y mujeres tanto en el plano biológico, psicológico y espiritual, ¿qué antropología es capaz de incluir a quienes no responden experiencial, identitaria y corporalmente a ese registro? ¿De qué modo habrán de vivir su espiritualidad si esta está constituida

14 Michelle González, Creada a imagen de Dios, (Bilbao: Mensajero, 2006), 22. En ese mismo sentido Tomichá afirma que en un proceso de gestación de ensayos teológicos «es fundamental una actitud de escucha, encuentro y diálogo» teniendo presente los nuevos escenarios $y$ las búsquedas de los sujetos emergentes. Roberto Tomichá Charupá, «Notas preliminares para una antropología teológico trinitaria" en Antropología Trinitaria, ed. CELAM (Bogotá: Centro de publicaciones del CELAM, 2014), 185-204, 185.

15 El Episcopado Argentino al referirse a las familias en el cambio de época y la necesidad de una nueva síntesis entre fe y vida, afirmaba en 2009 que «El temor frente a lo nuevo que se muestra confuso y desordenado, puede provocar en muchos agentes pastorales actitudes regresivas hacia una rígida defensa de lo «tradicional», endureciendo los discursos y las prácticas por la dificultad de asumir la nueva realidad vincular, interpretarla y reordenarla hacia una nueva y sana síntesis vital elaborada desde la fen. Conferencia Episcopal Argentina, Aportes para la pastoral familiar de la Iglesia en la Argentina, (Buenos Aires: CEA Oficina del libro, 2009), 22.

16 VM 4. Cf. 5. 
en razón del sexo biológico? ¿Qué imagen de Dios nos transmite una enseñanza que no abraza toda realidad humana en la realización enderezada de la vocación a la que estamos llamados/llamadas?

Si como bien afirma el documento, «la primera actitud de quien desea entrar en diálogo es escuchar», ${ }^{17}$ propongo que el primer paso para nuestras reflexiones no sea «escuchar y comprender lo que ha sucedido en las últimas décadas. El advenimiento del siglo $X X$, con sus visiones antropológicas», ${ }^{18}$ sino prestar una escucha atenta a las personas, con sus experiencias, sus sufrimientos y sus historias de vida, de modo tal que podamos razonar y proponer vinculando la sabiduría de la enseñanza eclesial con la vida de las personas para que realmente puedan vivir la vocación a la que han sido llamadas dónde y cómo se encuentren, inspiradas en el Evangelio.

El Papa Francisco entiende que la escucha

«significa prestar atención, tener deseo de comprender, de valorar, respetar, custodiar la palabra del otro. En la escucha se origina una especie de martirio, un sacrificio de sí mismo en el que se renueva el gesto realizado por Moisés ante la zarza ardiente: quitarse las sandalias en el "terreno sagrado" del encuentro con el otro que me habla». ${ }^{19}$

La otra persona es «terreno sagrado» donde la vida florece en la palabra que se dice y se recibe con reverencia, porque transmite una experiencia y es capaz de generar el encuentro compartiendo no solo certezas sino también dudas y preguntas. En el camino de la escucha habrá que hacer un éxodo, salir de la comodidad del territorio conocido y seguro recorriendo caminos junto a otras personas liberándose de cualquier presunción de omnipotencia para poner los propios dones al servicio del bien común.

$17 \mathrm{lbid} ., 8$. Cf. CEA, El Dios de la vida, 6.

$18 \mathrm{lbid} ., 8$.

19 Francisco, Mensaje del Santo Padre Francisco para la 50 Jornada Mundial de la Comunicaciones Sociales: Comunicación y misericordia: un encuentro fecundo (Vaticano: Librería Editrice Vaticana,2016), acceso el 12 de diciembre de 2019, http://w2.vatican.va/content/francesco/ es/messages/communications/documents/papa-francesco_20160124_messaggio-comunicazioni-sociali.html 
Propongo entonces la escucha atenta a la narración de una experiencia, sin «dirigir nuestra mirada hacia el otro con la finalidad de conocerlo, sino la de posibilitar que nos conozcamos en la mirada del otro, permitir que el otro nos alcance e inclusive que abra juicio sobre nosotros». ${ }^{20}$

Mi interés en este trabajo no será producir conocimiento acerca de la transexualidad ni plantear un discurso antropológico que la capture para «excluirla de», o la «inserte forzadamente» en una tradición de tendencia dualista y de configuración binaria. La misma complejidad de la situación demanda una reflexión atenta a la escucha de personas que nos solicitan con sus preguntas una comprensión válida de la sexualidad que pueda enriquecer sus vidas y a la vez que brinde un horizonte antropoteológico desde donde interpretar las nuevas expresiones de la sexualidad humana. Entre ellas, las que encarnan las personas transgénero y el modo en que se reconocen a sí mismas.

En la corriente viva del Evangelio anunciado por Jesús, transmitido en la Iglesia y que abraza todas las dimensiones existenciales de cada ser, también habremos de responder a la pregunta por ese Dios que creó a los seres humanos a su imagen y semejanza, y que en su creatividad infinita se deja ver en quienes pujan por descubrir quiénes están llamados/llamadas a ser.

\section{Un nuevo conjunto de conceptos}

Como muchos otros papás y mamás de niños y niñas transgénero, quienes comparten este testimonio, pueden evocar las primeras sensaciones que fueron provocando aquellas manifestaciones de su hijo de dos años que no respondían a lo que imaginaban con relación a las conductas habituales esperadas de su género: ${ }^{21}$

20 Segato, La crítica...12.

21 Ambos son médicos, tienen dos hijos, una niña transgénero de 9 años y un niño de 6 . Otros testimonios coinciden con lo que ellos narran, por razones de espacio no los he incluido. 
"Cuando mi esposa quedó embarazada hicimos la ecografía para que nos digan cuáles son sus genitales y cuál es su género. El especialista en imágenes nos dijo que iba a ser un varón porque vio que tenía pene y testículos. A partir de ese momento comenzamos a imaginar y proyectarnos en muchos aspectos y yo fui y le compré su primera ropita de bebé color celeste y me empecé a imaginar que cuando crezca iba a ser del mismo equipo de futbol, que íbamos a hacer cosas juntos... Ella proyectando el futuro, que íbamos a tener un varón... Hacia el segundo año de vida empezamos a ver algunas manifestaciones que nos llamaban la atención, relacionadas con mucha predilección con todo lo que es el mundo femenino, vestimentas, pelo largo, sus modales, posturas. Hicimos alguna consulta con el médico, con psicólogos y psicólogas que nos decían que los chicos juegan con diversas cosas y que después iba a dejar de jugar con eso e iba a jugar con autitos. Pero eso nunca pasó».

Tal como narran, hoy la tecnología anticipa la sorpresa de antaño. Con antelación al parto, la espera de un varón o de una mujer imprime un sello en los vínculos afectivos de la familia que lo va a hospedar. Biología que ya está interpretada histórica, cultural y socialmente hasta el punto de impactar en las decisiones que van tomando los adultos en torno al nacimiento y un imaginario que se concreta prontamente en actitudes, conductas, educación, juegos. Este engranaje simbólico que diferencia el modo en que se conciben la identidad y los comportamientos, el modo de ser y estar en el mundo de varones y mujeres en un momento histórico y social determinados, es denominado género. ${ }^{22}$

Hay abundante bibliografía que los recoge: Cf. R. Lucas Platero, Trans"exualidades; Patricia Soley-Beltrán, Transexualidad y la matriz heterosexual (Barcelona: Bellaterra, 2009); Andrés Gutiérrez, coord., Diversidad de identidades y roles de género (Madrid: Ministerio de Educación, cultura y deporte español, 2014); Gabriela Mansilla, «No me está diciendo que le gusta otro varón, me está diciendo que es niña», Revista Institucional de la Defensa Pública de la Ciudad Autónoma de Buenos Aires 14 (2018): 318-324; Gabriela Mansilla, Yo nena. Yo Princesa. Luana, la niña que eligió su propio nombre (Los Polvorines: Ediciones UNGS, 2014); José Serrano, ed., Otros cuerpos, otras sexualidades, (Bogotá: Pensar, 2006); Isidro García Nieto, «Infancias y adolescencias trans: herramientas y conocimientos para mejorar su abordaje» en Curso de Actualización Pediatría 2017 ed. AEPap. (Madrid: Lúa Ediciones 3.0, 2017), 19-26, edición en PDF; Ximena de Toro, «Niños y niñas transgéneros: ¿nacidos en el cuerpo equivocado o en una sociedad equivocada?», Revista Punto Género 5 (2015): 109-128; Aingeru Mayor, Tránsitos, 21-222.

22 Cf. Susana Gamba, Diccionario de estudios de género y feminismos, s.v. uestudios de género». La autora señala las divergencias que existen en torno a su conceptualización y la conveniencia o no de seguir usándolo. Cf. Marta Lamas comp., El género: la construcción cultural de la diferencia sexual, (México: Porrúa, 2013 ). 
Por tanto en las sociedades de todos los tiempos se ha esperado que las personas asuman comportamientos masculinos si son varones y femeninos si son mujeres, acorde a lo que las costumbres de cada época y lugar establecen sobre lo apropiado a cada uno/ una. Son los roles de género. Los roles de género no son fijos ni en las sociedades ni en las personas. Pueden cambiar a lo largo de la historia y de la vida. De hecho hay algunas personas que no se ajustan a las expectativas que disponen las sociedades sobre las expresiones apropiadas a cada género. Esta situación puede manifestarse desde muy temprana edad. Antes de los tres años los niños y niñas ya comúnmente desarrollan comportamientos típicos de cada género porque las familias, las instituciones y la misma sociedad los favorecen. Sin embargo hay niños y niñas que precozmente manifiestan conductas que varían de lo esperado para su género, aunque no siempre permanecen a lo largo de su vida. Cuando estos comportamientos se generalizan, persisten en el tiempo, se enuncian e incluso dan lugar en algunos casos a manifestaciones de disconformidad hacia las expresiones propias de lo que se espera de su género se habla de una persona transgénero. ${ }^{23}$

En ese mismo sentido

"Veíamos que tenía tendencia a vestirse, a disfrazarse y usar pelucas y pensábamos que íbamos a tener un hijo gay. En ese momento no sabíamos la diferencia entre orientación sexual y la identidad de género, a pesar de ser los dos médicos de profesión... no nos enseñaron esto. Fue pasando el tiempo y se volvió irritable, tenía dermatitis... nos pedía que los cumpleaños fueran de princesas de Disney y nosotros siempre teníamos una excusa y yo insistía para que los cumpleaños fueran de superhéroes. No entendíamos lo que pasaba».

23 El Programa de Género y Diversidad Sexual del Ministerio Público de la Defensa de CABA realizó una investigación sobre la situación del colectivo trans en la Ciudad de Buenos Aires en los últimos diez años. El informe final señala que ante la consulta acerca de la edad en que sintieron que su género era distinto del asignado al nacer, un $9,6 \%$ respondió desde el nacimiento y un $56 \%$ entre el primer año de vida y los 8 . Cf. Ministerio Público de la Defensa de CABA, La Revolución de las Mariposas (Ciudad Autónoma de Buenos Aires: Ministerio Público de Defensa, 2017) edición en PDF, 38. 
A la insistencia de las conductas infantiles se añade el desconcierto de los adultos. Dar nombre a lo que va sucediendo permite ir comprendiendo. Pero las familias no siempre cuentan con las herramientas y los conocimientos acordes a lo que se presenta. Esta indefinición genera confusión y ansiedad en quienes han de acompañar procesos.

Actualmente se cuenta con un nuevo conjunto de conceptos que permiten diferenciar diversas realidades. La ley de género vigente en nuestro país en su artículo 2 señala que «se entiende por identidad de género la vivencia interna e individual del género tal como cada persona la siente, la cual puede corresponder o no al sexo asignado al momento del nacimiento incluyendo la vivencia personal del cuerpo». ${ }^{24}$ Se denomina sexo asignado al consignado en la partida de nacimiento y en el documento nacional de identidad a partir de la observación de los genitales del recién nacido. ${ }^{25}$ Por tanto son llamadas cisgénero aquellas personas que se identifican con el sexo consignado en su nacimiento y transgénero quienes no se identifican con él. ${ }^{26}$ Como señalan Aznar y Tudela, no hay que equiparar a las personas transgénero con las personas intersex, quienes manifiestan variaciones en la constitución genotípica y fenotípica que ocasionan la presencia o bien de genitales ambiguos, o bien de rasgos virilizantes en mujeres o feminizantes en varones. ${ }^{27}$ Por otro lado, la orientación sexual hace referencia al apego afectivo

24 Ley $26743 / 2012$, Identidad de género, que establece el derecho a la identidad de género de las personas, sancionada el 9 de mayo de 2012 y promulgada el 23 de mayo de 2012 , acceso el 26 de enero de 2019 , http://www.ms.gba.gov.ar/sitios/tocoginecologia/files/2014/01/ Ley-26.743-IDENTIDAD-DE-GENERO.pdf

25 No hay que dejar de señalar que este concepto presenta sus dificultades. Algunos autores señalan que el sexo biológico no es otorgado a cada individuo en el momento del nacimiento sino el que posee desde su concepción Así, la identidad sexual es determinada genéticamente. Cf. Justo Aznar y Julio Tudela, "Aspectos biomédicos de la transexualidad» en Transexualidad, valoración pluridisciplinar del fenómeno y su regulación legal, coord., Justo Aznar (Valencia: Universidad Católica de Valencia San Vicente Mártir, 2017), 59-92; Eduardo López Aspitarte, «Estados intersexuales y cambio de sexo: aspectos éticos», Proyección 38 (1991): 131-141.

26 Los prefijos cis y trans quieren decir respectivamente estar al lado de, junto a o bien ir más allá, enfrente. En notas 2 y 3 se consignan algunas de las definiciones posibles.

27 Aznar y Tudela, «Aspectos biomédicos», 64. 
y sexual, a la atracción emocional hacia otras personas, tanto en las personas cisgénero como transgénero. ${ }^{28}$

Escuchar las voces de los testigos recorriendo este abanico de conceptos ayuda a percibir la complejidad de la situación que atraviesan. Habrá palabras que dejarán de usarse y se elegirán otras nuevas para dar sentido al nuevo rumbo que toma la vida familiar. La presencia y acompañamiento de profesionales de la salud, de la educación y del derecho que pueden ofrecer palabras a la incertidumbre familiar ante las expectativas sobre el comportamiento y la identidad de género de sus hijos e hijas, minimiza su angustia y reordena progresivamente la confusión inicial al generar una explicación de lo que van viviendo y facilitan el modo de resolver las situaciones que se irán planteando de allí en más. Y para las familias, el nuevo nombre elegido por sus hijos o hijas, abre las puertas a reconocimientos siempre nuevos y a hospedar al tú inesperado en el nosotros de la comunidad familiar. ${ }^{29}$

\section{Te he llamado por tu nombre, tú me perteneces (Is $\mathbf{4 3 , 1}$ )}

Alrededor de los cinco años de su hija, llegaron a la consulta de especialistas que pusieron palabras a lo que estaba viviendo.

28 La Organización Mundial de la Salud ha reclasificado en la versión del año 2018 de su Clasificación Internacional de enfermedades la transexualidad. Las identidades trans han sido eliminadas del capítulo de enfermedades mentales y pasará de formar parte del capítulo dedicado a los trastornos de personalidad y comportamiento-trastornos de la identidad de género al capítulo dedicado a las condiciones relativas a la salud sexual, denominándola incongruencia de género. De todos modos en la actualidad se pide insistentemente a la OMS que no incluya la transexualidad dentro de la Clasificación internacional de enfermedades. Conditions related to sexual health, sexual incongruenceen: OMS, ICD- 11 for Mortality and Morbidity Statistics (ICD- 11 MMS) 2018, acceso el 30 de abril de 2019, https://icd.who.int/browse 1 1/l-m/en\#/http\%3a\%2 f\%2 fid.who.int\%2ficd\%2 fentity\%2f411470068. En los últimos tiempos, se ha abierto un debate en relación con la conducta para tomar respecto del tratamiento y futuro de niños y niñas en esta situación. Como afirman los integrantes del Comité de ética del Hospital Ricardo Gutiérrez: «Este debate excede el ámbito médico tradicional y se extiende al social y al jurídico». Comité de Bioética Hospital de Niños Ricardo Gutiérrez, «Reflexiones del Comité de Bioética de un hospital pediátrico sobre las implicancias del diagnóstico y tratamiento de los trastornos del desarrollo sexual», Arch Argent Pediatr 113 (2015): 260-264, edición en PDF, 260.

29 El artículo 12 de la Ley de Identidad de Género consigna la importancia de llamar a las personas transgénero por el nombre que han elegido como una dimensión esencial del trato digno. 
«Nos dijeron que les parecía que se trataba de una niña transgénero... En ese momento pensamos que era un problema pero no, solamente era acompañar. Acompañarla desde el amor, decirle que la queríamos, que la íbamos a respetar y a querer independientemente de la ropa que quiera usar, del largo del pelo, del nombre. Nos sentamos y le dijimos esto, que siempre la íbamos a acompañar y ella nos miró como diciendo: bueno, ya era hora de que me dejen ser... Ella va a un colegio religioso y nos dijo algo relacionado con Jesús. Que si nosotros la respetamos a ella y la queremos, estaríamos haciendo lo que hace Jesús con todas las personas».

«Lo que Jesús hace con todas las personas». Bellas palabras para expresar cómo las madres y los padres (y quienes acompañan el cuidado) pueden ser reflejo del amor de Dios manifestado en su Hijo, cuando aman a sus hijos e hijas tal cual son. Recordando aquellas palabras de Jesús, dichas también para quienes atraviesan la crianza como un tiempo de tránsito, «estaba de paso, y me alojaron» (Mt 25,35); la hospitalidad se convierte en un camino espiritual para vivir la diversidad. Verse transformado por la llegada de un tú inesperado, recibido incondicionalmente, inscribiendo dinámicamente el intercambio recíproco como un aprendizaje mutuo, de idiomas, de tiempos, de búsquedas, con un nombre nuevo, actualiza la exhortación de Pablo a recibirnos mutuamente como Cristo nos recibe, para gloria de Dios (Rom 15,7). A imagen de la hospitalidad del buen Dios que recibe a todos/todas, en la Iglesia, como familia de familias, la hospitalidad no solo se construye con gestos exteriores, esporádicos, sino que ha de brotar de su misma entraña, como un modo de ser centrado en las personas y para las personas tal cual son.

«Lo que Jesús hace con todas las personas». En esta afirmación se condensa una teología de la misericordia que tiene su fuente y origen en el amor desbordante de la Trinidad y que expresa con su vida Jesucristo, «rostro de la misericordia del Padre»..0

30 Francisco, Misericordiae vultus (Roma, Librería Editrice Vaticana, 2015), 1, acceso 25 de enero de 2019, http://w2.vatican.va/content/francesco/es/bulls/documents/papa-francesco_bolla_20150411_misericordiae-vultus.html. Walter Kasper afirma que la misericordia ha de convertirse en organizador de los atributos divinos. Walter Kasper, La misericordia. Clave del evangelio y de la vida cristiana (Santander: Sal Terrae, 2012), 92. 
«Misericordia es la palabra que revela el misterio de la Santísima Trinidad. Misericordia es el acto último y supremo con el cual Dios viene a nuestro encuentro. Misericordia es la ley fundamental que habita en el corazón de cada persona cuando mira con ojos sinceros al hermano que encuentra en el camino de la vida».31

En la misericordia que habita en el corazón y se trasluce en mirar a las personas «con la mirada de Dios Padre»," reconocemos que cada persona tiene derecho a ser feliz. Si algo podemos vislumbrar de la Trinidad en el rostro de un tú diverso es la amorosa creatividad de un Dios misericordioso que siendo comunión tripersonal nos llama a «estar-y-vivir-en-relación».33

El origen fontal de relaciones hospitalarias y misericordiosas es el mismo Dios Trinidad que sale al encuentro de todo tú y abraza a todas las personas, quienes pueden descubrir en la variada riqueza de la creación, una huella de su presencia vivificante en la infinita creatividad de su amor desbordante. La misma sabiduría creadora, fuente viva sin origen de todo cuanto existe, en su «inimaginable capacidad de vida, genera la vida de todas las creaturas, siendo ella misma, el principio y continuamente, el poder ser de todo ser». ${ }^{34}$ A cada una le dice: es bueno que existas, también a quienes han ido descubriendo un modo diverso de sentir, expresar $y$ vivir su sexualidad. ${ }^{35}$

31 Francisco, Misericordiae vultus, 2.

$32 \mathrm{El}$ amor nos lleva a una sentida valoración de cada ser humano, reconociendo su derecho a la felicidad. «Amo a esa persona, la miro con la mirada de Dios Padre que nos regala todo para que lo disfrutemos». Francisco, Amoris Laetitia (Bilbao: Mensajero, 2016), 96.

33 Gonzalo Zarazaga, «Aportes para una teología de comunión», Stromata (2006): 151166,166. Las consecuencias antropológicas de esta afirmación Zarazaga las vincula con «el respeto que hoy se demanda a cada persona, por las minorías, por los más pobres (...) comunionalmente implicados en un mismo mundo y un mismo destino, vinculado y vinculante", Ibid., 66. Cf. Conzalo Zarazaga, «Hacia una antropología trinitaria» en Antropología trinitaria para nuestros pueblos, ed. CELAM (Bogotá: Centro de publicaciones del CELAM, 2014), 51-74.

34 Elizabeth Johnson, La que es (Barcelona: Herder, 2002), 235

35 El documento, Varón y mujer los creó, asume que la identidad de género no se descubre sino que se elije, siendo una opción individualista y autónoma que niega la realidad ontológica de la dualidad humana y vacía la base antropológica de la familia. Cf. VM, 2, 1 1, 14, 21, 22, 34 y CEA, El Dios de la vida, 6 . Los estudios sobre la transexualidad no hablan de libre elección sino de progresivo descubrimiento de la propia identidad sexual. Cf. Nora Barqui, Gabriel Genise, Dante Tolosa, Manual integrador hacia la despatologización de las identidades trans (Buenos Aires: Akadia, 2018). 


\section{Somos transfigurados a su propia imagen con un esplendor cada vez más glorioso $(2$ Co 3,18$)$}

Las primeras páginas del Génesis revelan el secreto de nuestra identidad más profunda: el ser humano ha sido creado «como imagen y semejanza de Dios», afirmación que "constituye la base inmutable de toda antropología cristiana». ${ }^{36}$ Todos lo miembros de la especie son favorecidos por igual con la identidad teológica de imago Dei. Somos teomorfos, teomorfas. Con estas palabras se afirma una verdad axiológica más que ontológica: el ser humano es el valor más alto de la creación. En palabras de Teresa Porcile «ser creados a imagen de Dios es la base antropológica para toda relación de justicia». ${ }^{37}$

El Dios Trinidad que nos ha creado a su imagen y semejanza en Cristo, se ha encarnado como varón, sin embargo todo misterio humano se comprende a la luz del verbo encarnado y la salvación que nos trae alcanza a la humanidad entera, sin exclusiones. Por tanto no solo reflejamos la imagen del creador en las capacidades racionales y espirituales sino que el ser humano es imagen y semejanza de Dios en su realidad concreta, corporal e interiormente abrazando «todas sus dimensiones por el germen divino que en él habita», ${ }^{38}$ en relación con su hacedor providente.

Así, toda persona, como "totalidad integrada», ${ }^{39}$ es capaz de reflejar esa imagen crística y la salvación que ofrece en su pascua liberadora alcanza también toda condición e identidad humana. Ya

36 Juan Pablo II, Mulieris dignitatem (Buenos Aires: Paulinas, 1988), 6

37 Teresa Porcile, La mujer espacio de salvación (Madrid: Claretianas, 1995), 188. Cf. VM, 30, José L. Sicre, El Pentateuco. Introducción y textos selectos, (Buenos Aires: San Benito, 2004), 84-88; Elizabeth Johnson, La que es...102-103; María Clara. Bingemer, Um rostro para Deus? (Sao Paulo: Paulus, 2005), 106; Hans. Wolff, Antropología del Antiguo Testamento (Salamanca, Sígueme: 1975), 216-219; Lona Horacio, Qué es el hombre para que te acuerdes de él (Buenos Aires: Claretiana, 2008), 31-46. Juan Ruiz de la Peña advierte que lo que en los textos bíblicos se aproxima a un planteamiento ontológico es modesto, enumera los siguientes aspectos: la unidad del ser humano, su contingencia y su relacionalidad. Cf. Juan Ruiz de la Peña, Antropología teológica fundamental (Santander: Sal Terrae, 1996), 50.

38 Luis Ladaria, Introducción a la antropología teológica (Estella: Verbo Divino, 1992), 62.

39 Eloísa Ortiz de Elguea, No podrán apagar el amor (Buenos Aires: Claretiana, 2017), 109-110. 
Pablo recordaba que revestidos de Cristo ya no hay judío ni griego, esclavo ni hombre libre, varón ni mujer porque somos uno en Cristo Jesús (Gal 3,28).

\section{Amas a todos los seres y nada de lo que hiciste aborreces (Sab 11,24)}

Para una vía de diálogo sobre la cuestión de gender en la educación, la Congregación para la Educación Católica eligió como título del documento: Varón y mujer los creó. ${ }^{40}$ Este título llevó a preguntarme cómo leen estas palabras del Génesis las personas que no se sienten identificadas plenamente con ellas por su identidad de género. El binarismo sexual, ligado intrínsecamente a la biología y a la heterosexualidad, es un dato que hemos sostenido hasta el momento, en las sucesivas relecturas e interpretaciones de aquel texto. Sin embargo, otras referencias del mismo capítulo, relativas al origen del cosmos, de la vida, de los astros, de las diversas especies y del mismo ser humano fueron adquiriendo nuevas explicaciones gracias al aporte del avance científico. Habría que cuestionarse si hay algún motivo que impida preguntarle al texto bíblico los alcances de esta afirmación en el actual contexto, que demanda respuestas referidas a las diversas formas de encarnar la sexualidad. Como el mismo Catecismo reconoce, estos textos no pretenden responder a cuestiones científicas sino a las preguntas existenciales de la vida: de dónde venimos, a dónde vamos, de dónde viene y a dónde va todo lo que existe. ${ }^{41}$

$40 \mathrm{El}$ documento, fundado en ellas, propone reiterar la raíz metafísica de la diferencia sexual: «de hecho el hombre y la mujer son las dos formas en que se expresa y se realiza la realidad ontológica de la persona humana» VM, 34. Vale recordar que el ambiente vital en el que surge el texto bíblico, desconoce las categorías metafísicas. Al mismo tiempo es necesario aclarar que las palabras del Génesis no se corresponden exactamente con esta traducción sino que refieren a los términos macho-hembra. En el contexto epocal en el que se inscribe el texto, la condición sexual estaba orientada a la reproducción, como indican tanto las palabras que designan macho y hembra (zajar/uneqevá) como la orden de crecer y multiplicarse. El pueblo habría de prolongar su estirpe en medio de una situación crítica como era el destierro. Teresa Porcile, La mujer espacio de salvación, 191-194.

41 Cf. Cf. Catecismo de la Iglesia Católica (Buenos Aires: Claretiana, 1993), 282. 
Si «la Biblia es palabra de Dios para todas las épocas que se suceden ${ }^{42}$ como afirma el documento La interpretación de la Biblia en la Iglesia, es necesaria una hermenéutica que, constatando las distancias culturales entre los autores y lectores, pueda enlazar sus experiencias creyentes. Por tanto los cuestionamientos existenciales de todas las épocas, latentes y presentes en los textos bíblicos y sus respuestas, también habrán de alcanzar a quienes leen la Escritura desde una identidad de género que la Biblia no explicita conceptualmente porque las situaciones culturales de los tiempos antiguos no son las nuestras. ${ }^{43}$

\section{El Verbo se hizo carne $(\mathrm{Jn} 1,14)$}

La teología contemporánea ha ido superando una concepción dualista del ser humano y negativa del cuerpo dando paso a una antropología capaz de integrar la totalidad de lo humano. Un cam-

42 Pontificia Comisión Bíblica, La Interpretación de la Biblia en la Iglesia (Buenos Aires: Paulinas, 1993), 71 .

43 La Pontificia Comisión Bíblica ha publicado recientemente (diciembre de 2019) un estudio sistemático sobre la visión antropológica de la Escritura, desde el Génesis hasta el Apocalipsis. Entrevistado por Alessandro De Carolis, el jesuita Pietro Bovati, asegura que en el texto sagrado están los principios para reflexionar sobre las grandes cuestiones contemporáneas. "Nos parece que hemos respondido precisamente a lo que la Iglesia nos pide, es decir, no decir cosas que no son lo que la Biblia nos presenta. (...) Hay preguntas que la gente se hace hoy que no encuentran una respuesta inmediata y precisa en la Escritura, porque las situaciones culturales de los tiempos antiguos no son las nuestras. (...) Por tanto, la Biblia ofrece algunos principios, algunas indicaciones útiles para una reflexión que, sin embargo, se confía también a otros intérpretes del pensamiento cristiano, como teólogos, moralistas, pastores, para poder responder más adecuadamente a la pregunta que el hombre dirige en todo caso a la Iglesia». Alessandro De Carolis. ¿Quién es el hombre? La respuesta de la Biblia explicada por los teólogos del Papa (Ciudad del Vaticano:Vaticans news, 2019), acceso el 19 de diciembre de 2019. https://www.vaticannews. va/es/vaticano/news/2019-12/hombre-pontificia-comision-biblica.html. El documento ha sido editado en italiano con el nombre: Che cosa è l'uomo? Un itinerario di antropologia biblica mientras terminaba de escribir este texto, por lo que no tuve posibilidad de acceder a él ni en papel ni digitalmente. A este trabajo hay que sumar los desarrollos de interpretación bíblica elaborados desde las teorías queer. "Las teorías queer emergieron hacia fines del siglo XX a partir de las experiencias de sujetos y subjetividades que eran marginadas por su sexualidad (gay, lesbiana, bisexual) o su identidad de género (transexual, intersexual, no binario)", Stefanie Knauss y Carlos Mendoza, «Editorial», Concilium 383(2019):7. Cf. Joseph Marchal, «Estudios queer y estudios críticos de la masculinidad en los estudios bíblicos feministas» en La exégesis ferninista del siglo $X X$, ed. Elisabeth Schüssler Fiorenza (Estella: Verbo Divino, 2015), 281-300; Gerald West y Charlene van der Welt, «Un comienzo queer de la Biblia», Concilium 383 (2019): $117-128$. 
bio que de «sentir el cuerpo como un objeto rechazado o disfrutado, nos lleve a sentirnos cuerpo». ${ }^{44}$

Si la carne es el quicio de nuestra salvación ${ }^{45}$ toda corporalidad humana ha sido asumida y abrazada por el Hijo. Dios en Cristo se ha revelado al ser humano haciéndose cuerpo, los cuerpos son lenguaje capaz de expresar la interioridad como significantes, ${ }^{46}$ son «epifanía del yo», ${ }^{47}$ lavados, ungidos, sanados en su pascua.

Más allá del determinismo biológico, urge pensarnos como personas con nuestras biologías y biografías en el entramado plural de nuestro tiempo y de las culturas. Personas como «yoes», ${ }^{48}$ «autopresencias en relación», ${ }^{49}$ que van siendo y deviniendo como pregunta y respuesta por el propio misterio, búsqueda infinita de sentido en la múltiple referencia e intercambio con otros tús y el ambiente vital que la rodea. Una comprensión dinámica y pluridimensional de la persona, que no limite su humanidad a la condición sexual, sino que sea capaz de distinguir sin separar sexo y cultura. ${ }^{50}$

La identidad humana se estructura gracias al entrecruzamiento de diversas realidades: «corporalidad, relaciones personales, relaciones estructurales, contexto temporal y espacial, cultura y orientación al futuro». ${ }^{51}$ La identidad de género, en este escenario, se inscribe en la comprensión cada vez menos estática del ser humano, una comprensión histórica y pluridimensional de la humanidad en la cual la autorrealización es el devenir-yo de la persona ${ }^{52}$ en el contexto fluido de un incesante crecimiento en y gracias al desarrollo relacional

44 Nunzio Galantino, «El cuerpo más allá del platonismo», Selecciones de Teología 183 (2007): $181-188,188$.

45 Tertuliano, De carnis resurrectione, 6. Citado por Ruiz de la Peña, Imagen de Dios, 96.

46 Teresa Porcile, La mujer espacio de salvación, 231-238.

47 Marta Manzanares, «El cuerpo lugar de encuentro», Theologica Xaveriana 116 (1995): 407-418, 411. Cf. Porcile, La mujer espacio de salvación, 232-238; Ortiz de Elguea, No podrán apagar el amor, 19-22 y $109-110$.

48 Expresión de Ann O'Hara citada por Michelle González en: Creadas a imagen de Dios, 179.

49 Barbara Andrade, Dios en medio de nosotros (Salamanca: Secretariado Trinitario, 1999), 112.

50 Francisco, Amoris Laetitia, 56.

51 González, Creada a imagen de Dios, 169.

$52 \mathrm{Cf}$. Andrade, Dios en medio de nosotros, 109-113. 
dentro de los propios condicionamientos concretos. Por tanto, la correlación anatomía-identidad no es estática ni lineal, como tampoco lo es el modo en que los varones viven su masculinidad, las mujeres su feminidad y las personas transgénero su propia identidad. Como afirma Bedford «teológicamente, esa fluidez es una buena noticia: quiere decir que podemos cambiar» ${ }^{53}$.

\section{Una conclusión inacabada}

Escuchando las demandas de las personas transgénero y sus familias y del entorno pedagógico en el que se presentan nuevos desafíos antropológicos en torno a la sexualidad esbocé, a lo largo de estas páginas, una serie de conceptos clarificadores acerca de la diversidad sexual y algunas posibles vías de reflexión teológica inscriptas en la teología de la creación y en la antropología teológica. Queda pendiente para otro estudio profundizar los textos de Génesis 1 y 2 y la enseñanza paulina de Gálatas 3,28 en relación con estas experiencias.

Puse especial énfasis en la identidad teomórfica y cristomórfica, como una afirmación fundante de una antropología inclusiva. Como afirma San Pablo, siendo imágenes de Cristo, reflejamos como en un espejo la gloria de Dios $(2$ Co 3,18$)$. Nuestra existencia humana es así sacramental, por tanto habrá que seguir imaginando nuevos modos de pensar lo humano que sean capaces de afirmar esa sacramentalidad para todos los cuerpos e identidades tendiendo puentes de diálogo, respeto, compasión y sensibilidad. ${ }^{54}$

Las infancias trans nos desafían a pensar los cuerpos y sexualidades de un modo nuevo. Territorios aún poco explorados por la teología y que en estas páginas solo se ha pincelado como un bo-

53 Nancy Berdford, «Sexwalidad y género desde una perspectiva teológica» en Cuerpos, historicidad y religión, ed. Lucía Riba y Eduardo Mattio (Córdoba: EDUCC, 2013), 159-180, 170.

54 Cf. Catecismo de la Iglesia Católica, 2358 y el desarrollo de estos conceptos en relación con la comunidad LGTBI por James Martin, Tender un puente (Bilbao: Mensajero, 2018), 43-1 14. 
ceto inacabado. Pensar lo humano tanto en su desarrollo histórico personal, como un ser en desarrollo, siendo con y gracias a otras personas, como también profundizar en la incidencia del dinamismo social y cultural en la identidad de los sujetos, puede ayudar a madurar una antropología que evite fixismos esencialistas.

Termino este texto en vísperas de la Navidad y ya resuenan las palabras del Evangelio de Lucas: «lo acostó en un pesebre, porque no tenían sitio en el albergue» (Lc 27). Ojalá que como Iglesia podamos ser ese albergue siempre abierto a recibir y hospedar a todas las personas.

\section{Bibliografía}

Aragno, Iván. Sexualidad humana. México D.F: Manual Moderno, 2008.

Aznar, Justo y Julio Tudela. «Aspectos biomédicos de la transexualidad». En Transexualidad, valoración pluridisciplinar del fenómeno y su regulación legal, ed. Justo Aznar. Valencia: Universidad Católica de Valencia San Vicente Mártir, 2017.

Barqui, Nora, Gabriel Genise, Dante Tolosa, Manual integrador hacia la despatologización de las identidades trans. Buenos Aires: Akadia, 2018.

Berdford, Nancy. «Sexualidad y género desde una perspectiva teológica». En Cuerpos, historicidad y religión, ed. Lucía Riba y Eduardo Mattio. Córdoba: EDUCC, 2013.

Bingemer, María Clara. Um rostro para Deus? Sao Paulo, Paulus: 2005.

Catecismo de la Iglesia Católica. Buenos Aires: Claretiana, 1993.

Comité de Bioética Hospital de Niños Ricardo Gutiérrez, «Reflexiones del Comité de Bioética de un hospital pediátrico sobre las implicancias del diagnóstico y tratamiento de los trastornos del desarrollo sexual», Arch Argent Pediatr 113 (2015): 260264. Edición en PDF. 
Compagnoni Francesco, Giannino Piana, Salvatore Privitera, Marciano Vidal. Nuevo diccionario de teología moral. Madrid: Paulinas, 1992.

Conferencia Episcopal Argentina. El Dios de la vida y del amor humano. Buenos Aires: CEA, Oficina del libro, 2019.

Congregación para la Educación Católica. Varón y mujer los creó. Ciudad del Vaticano: Editrice Vaticana, 2019. Edición en PDF.

de Toro, Ximena. « Niños y niñas transgéneros: ¿nacidos en el cuerpo equivocado o en una sociedad equivocada?», Revista Punto Género 5 (2015): 109-128.

Francisco. Amoris Laetitia. Bilbao: Mensajero, 2016.

Galantino, Nunzio. «El cuerpo más allá del platonismo», Selecciones de Teología 183 (2007):181-188.

Gamba, Susana. Diccionario de estudios de género y feminismos. Buenos Aires: Biblos, 2007.

García Nieto, Isidro. «Infancias y adolescencias trans: herramientas y conocimientos para mejorar su abordaje». En Curso de Actualización Pediatría 2017, ed. AEPap., Madrid: Lúa Ediciones 3.0, 2017. Edición en PDF.

Gómez, Javier. Psicología de la sexualidad. Madrid: Alianza, 2018.

González, Michelle. Creada a imagen de Dios. Bilbao: Mensajero, 2006.

Gutiérrez, Andrés, coord., Diversidad de identidades y roles de género. Madrid: Ministerio de Educación, cultura y deporte español, 2014.

Johnson, Elizabeth. La que es. Barcelona: Herder, 2002.

Kasper, Walter. La misericordia. Clave del evangelio y de la vida cristiana. Santander: Sal Terrae, 2012.

Ladaria, Luis. Introducción a la antropología teológica. Estella: Verbo Divino, 1992.

Ley 26150/2006. Programa Nacional De Educación Sexual Integral. Acceso el 26 de enero de 2019. https://www.buenosaires. gob.ar/sites/gcaba/files/ley2110.pdf 
Ley 26743/2012. Identidad de género. Acceso el 26 de enero de 2019. http://www.jus.gob.ar/media/3108867/ley_26743_identidad_ de_genero.pdf

Lona, Horacio. Qué es el hombre para que te acuerdes de él. Buenos Aires: Claretiana, 2008.

López Aspitarte, Eduardo. «Estados intersexuales y cambio de sexo: aspectos éticos», Proyección 38 (1991): 131-141.

Mansilla, Gabriela Yo nena. Yo Princesa. Luana, la niña que eligió su propio nombre. Los Polvorines: Ediciones UNGS, 2014.

Mansilla, Gabriela. «No me está diciendo que le gusta otro varón, me está diciendo que es niña», Revista Institucional de la Defensa Pública de la CABA 14 (2018): 318-324.

Manzanares, Marta. «El cuerpo lugar de encuentro», Theologica Xaveriana 116 (1995): 407-418.

Martin, James. Tender un puente. Bilbao: Mensajero, 2018.

Mayor, Aingeru. Tránsitos. Barcelona: Bellaterra, 2020.

Ministerio Público de la Defensa de la CABA. La Revolución de las Mariposas. Ministerio Público de Defensa: Ciudad Autónoma de Buenos Aires, 2017. Edición en PDF.

Platero, R.Lucas. Trans*exualidades, acompañamiento, factores de salud y recursos educativos. Barcelona: Bellaterra, 2014.

Porcile, Teresa. La mujer espacio de salvación. Madrid: Claretianas, 1995.

Rathus, Spencer, Jeffrey Nevid, Lois Fichner. Sexualidad humana. Madrid: Pearson Educación, 20056.

Ruiz de la Peña, Juan. Antropología teológica fundamental. Santander: Sal Terrae, 1996.

Segato, Rita. Contra-pedagogía de la crueldad. Buenos Aires: Prometeo, 2018. 
Segato, Rita. La crítica de la coloniedad en ocho ensayos. Buenos Aires: Prometeo, 2013.

Serrano, José, ed., Otros cuerpos, otras sexualidades. Bogotá: Pensar, 2006.

Shibley, Janet, John DeLamater. Sexualidad humana. México: McGraw-Hill, 2003'.

Sicre, José L. El Pentateuco. Introducción y textos selectos. Buenos Aires: San Benito, 2004.

Soley-Beltrán, Patricia. Transexualidad y la matriz heterosexual. Barcelona: Bellaterra, 2009.

Tomichá Charupá, Roberto. «Notas preliminares para una antropología teológico trinitaria». En Antropología Trinitaria, ed. CELAM. Bogotá: Centro de publicaciones del CELAM, 2014.

West Gerald y Charlene van der Welt, «Un comienzo queer de la Biblia », Concilium 383(2019): 117-128.

Wolff, Hans. Antropología del Antiguo Testamento. Salamanca: Sígueme, 1975.

Zarazaga, Gonzalo. «Hacia una antropología trinitaria». En Antropología trinitaria para muestros pueblos, ed. CELAM. Bogotá: Centro de publicaciones del CELAM, 2014.

Zarazaga, Gonzalo. «Aportes para una teología de comunión», Stromata (2006):151-166. 